\title{
Protocolo de manejo de suspeita de infecção viral de vias respiratórias em pacientes com neoplasia hematológica do serviço de hematologia e transplante de medula óssea do Hospital Universitário Walter Cantídio (HUWC)
}

\section{Management protocol of suspected viral infection from respiratory tract in patients with hematologic malignancy of the hematology and bone marrow transplant service of Walter Cantídio University Hospital (HUWC)}

Élida Lívia Rafael Dantas ${ }^{1}$. Luany Elvira Mesquita Carvalho ${ }^{1}$. Beatriz Stela Gomes de Souza Pitombeira Araújo ${ }^{1}$. Maria da Silva Pitombeira ${ }^{1}$. Caroline Mary Gurgel Dias Florêncio ${ }^{2}$. Fernanda Edna Araújo Moura ${ }^{2}$. Daniel Mazza ${ }^{1}$. Eveline Santana Girão . Jacques Kaufman $^{1}$. João Paulo Vasconcelos Leitão ${ }^{1}$. Jorge Luiz Nobre Rodrigues ${ }^{1}$. Karine Sampaio Nunes Barroso ${ }^{1}$. Rosângela de Albuquerque Ribeiro ${ }^{1}$. Fernando Barroso Duarte ${ }^{1}$.

1 Hospital Universitário Walter Cantídio. 2 Departamento de Patologia e Medicina Legal da Universidade Federal do Ceará.

RESUMO

Infecção respiratória viral é causa significativa de morbi-mortalidade em paciente com doenças hematológicas. Deve ser suspeitado sempre que houver sintomas como coriza, obstrução nasal, odinofagia, tosse e dispnéia e deve-se seguir à identificação viral, quando possível. Os casos podem ser classificados como possível, provável ou confirmado. E observando-se o risco de progressão da infecção para vias aéreas inferiores, o diagnóstico deve ser precoce e as medidas terapêuticas específicas aos vírus bem como medidas de controle da infecção no ambiente hospitalar devem ser prontamente tomadas. O presente trabalho visa descrever um protocolo de manejo da infecção viral de vias respiratórias em pacientes com neoplasia hematológica dentro do Serviço de Hematologia e Transplante de medula do Hospital Universitário Walter Cantídio.

Palavras-chave: Neutropenia febril. Infecção respiratória. Vírus.

ABSTRACT

Viral respiratory tract infection is a significative cause of mobimortality in hematological patients. Should be suspected whenever be sintoms as runny nose, nasal obstruction, sore throat, cough and dyspnea. It must to identify the virus, when possible. The cases can be classified as possible, probable or confirmed. And noting the risk of infection progression for respiratory lower tract, the diagnosis has to be premature and the especifics terapeutic measures and infection control in the hospital should tb promptly taken. The main aim of this study was to describe a management protocol viral infection of the respiratory tract in patients with hematologic malignancy within the Hematology and Marrow transplantation Service of Walter Cantídio University Hospital.

Keywords: Febrile neutropenia. Respiratory tract infection. Virus.

Autor correspondente: Élida Lívia Rafael Dantas. Rua Frei Mansueto, 333, Apto 1201, Meireles, Fortaleza, Ceará. CEP:60175-070. Telefone: +55 859969 8286/3366 8623. E-mail: elidadantas@yahoo.com.br.

Conflito de interesses: Não há qualquer conflito de interesses por parte de qualquer um dos autores.

Recebido em: 23 Mar 2015; Revisado em: 24 Abr 2015; Aceito em: 24 Abr 2015. 


\section{INTRODUÇÃO}

Infecção de vias respiratórias virais (IRV) é considerada uma causa significativa de morbidade e mortalidade em pacientes hematológicos e pós-transplante de células tronco hematopoéticas (TCTH). ${ }^{1}$

A progressão de uma IRV alta para as vias aéreas inferiores depende de fatores específicos do hospedeiro, como doenças de base e terapêutica; assim como da virulência dos agentes virais envolvidos. ${ }^{1}$

A identificação viral nas amostras clínicas pode ser feita por métodos de amplificação de ácido nucléico, detecção de antígeno e isolamento viral em cultura de células. ${ }^{1}$

O manejo clínico das IRV inclui terapia de suporte e antiviral específica, a exemplo do uso dos inibidores de neuraminidase no caso de infecções pelo vírus influenza. Devido à falta de tratamento específico para a maioria dos outros vírus, a prevenção deve ser enfatizada; portanto, o diagnóstico precoce permite tratamento imediato e orienta medidas de controle de infecção no ambiente hospitalar. $^{2}$

O presente trabalho visa descrever um protocolo de manejo da infecção viral de vias respiratórias em pacientes com neoplasia hematológica dentro do Serviço de Hematologia e Transplante de medula do Hospital Universitário Walter Cantídio.

\section{CONCEITOS}

Classificação de caso:

- Caso possível: critérios clínicos para IRV;

- Caso provável: critérios clínicos associado à epidemiologia para IRV;

- Caso confirmado: critério clínico associado a critério laboratorial.

Critérios clínicos:

- Sintomas novos e no mínimo, um dos 4 sintomas respiratórios:

- Tosse

- Garganta inflamada

- Dispnéia

- Coriza

- E julgamento clínico de que os sintomas são secundários à infecção.

Critério epidemiológico

- Um link epidemiológico à transmissão humano-ahumano: atividade na comunidade, contato com visitantes, outro paciente, profissional de saúde.

Critério laboratorial

- Detecção de vírus respiratórios através de métodos laboratoriais e exclusão de outro tipo de infecção. ${ }^{1}$

\section{Dados epidemiológicos do Serviço de Hematologia/TMO do HUWC}

Durante o período de agosto de 2012 a abril de 2014, foram internados cerca de 524 pacientes no serviço de Hematologia e TMO do HUWC. Foram registrados 19 pacientes que apresentaram sintomas respiratórios altos, tais como coriza, tosse e obstrução nasal. Desses, 10 casos foram confirmados de infecção por vírus respiratórios. Dentre esses, 6 casos foram de Parainfluenza $3(31,57 \%) ; 2$ casos de Vírus Sincicial Respiratório $(10,52 \%)$ e 2 casos de Influenza A $(10,52 \%)$ que foram subtipados como H3N2 e foi iniciado terapêutica com Oseltamivir.

\section{Manejo da suspeita de IRV em pacientes internados no Serviço de Hematologia/TMO do Hospital Universitário Walter Cantídio.}

Pacientes com sintomas respiratórios altos, tais como coriza, tosse e obstrução nasal devem ser submetidos à pesquisa de infecção viral através da coleta de aspira do nasofaríngeo.

A coleta é realizada através da equipe de virologia da Professora Doutora Fernanda Edna no laboratório de Virologia do Departamento de Patologia e Medicina Legal da Universidade Federal do Ceará, no horário de 7h-17h, de segunda à sexta-feira.

O material é submetido à imunofluorescência indireta e, ocasionalmente, ao $\mathrm{PCR}$, com resultados rápidos, permitindo medidas precoces.

Diante de infecções pelo vírus Influenza, uma amostra de aspirado nasofaríngeo deve ser enviada ao LACEN (Laboratório Central), para que seja identificado o subtipo do vírus, medida importante para epidemiologia e controle de infecção viral.

- Recomendações para a prevenção e medidas de controle em ambiente hospitalar

- Boa higiene pessoal: lavagem das mãos freqüente, cobrir boca e nariz ao espirrar e tossir, descartar apropriadamente secreções nasais e orais;

- Evitar visitantes crianças visto o maior risco de exposição aos vírus;

- Proibir visitantes com sinais e sintomas de infecção respiratória;

- Quartos de isolamento e medidas de proteção rígidas: luvas, máscaras, proteção para olhos tanto para os pacientes, quantos para os visitantes, quanto para os profissionais de saúde. ${ }^{1}$

- Recomendações de tratamento para pacientes Hematológicos/TMO (Algoritmo 1)

- Avaliar condicionamento, protocolos de quimioterapia e agendamento nesses pacientes com IRV e, se possível, adiar o procedimento; 
- Pacientes com infecção pelo vírus Influenza devem iniciar a terapia em até 24-48 horas do início dos sintomas com inibidor da neuraminidase: Oseltamivir (Tamifluß) na dose de $150 \mathrm{mg}, \mathrm{VO}, 12 / 12 \mathrm{~h}$ por 10 $\operatorname{dias} ;^{3}$

- $\mathrm{Na}$ impossibilidade de coleta de aspirado nasofaríngeo para pesquisa viral em até 48 horas do início dos sintomas, deve-se iniciar terapia com Oseltamivir (Tamiflu $\AA$ ) na dose de $150 \mathrm{mg}$, VO, 12/12h por 10 dias;

- A PROFILAXIA para vírus Influenza deve ser iniciada até 48 horas após a exposição ao vírus Influenza com Oseltamivir (Tamiflu $\left.{ }^{\circledR}\right)$ na dose de $75 \mathrm{mg}, \mathrm{VO}, 1 \mathrm{x} /$ dia por 10 dias.

Algorítimo 1

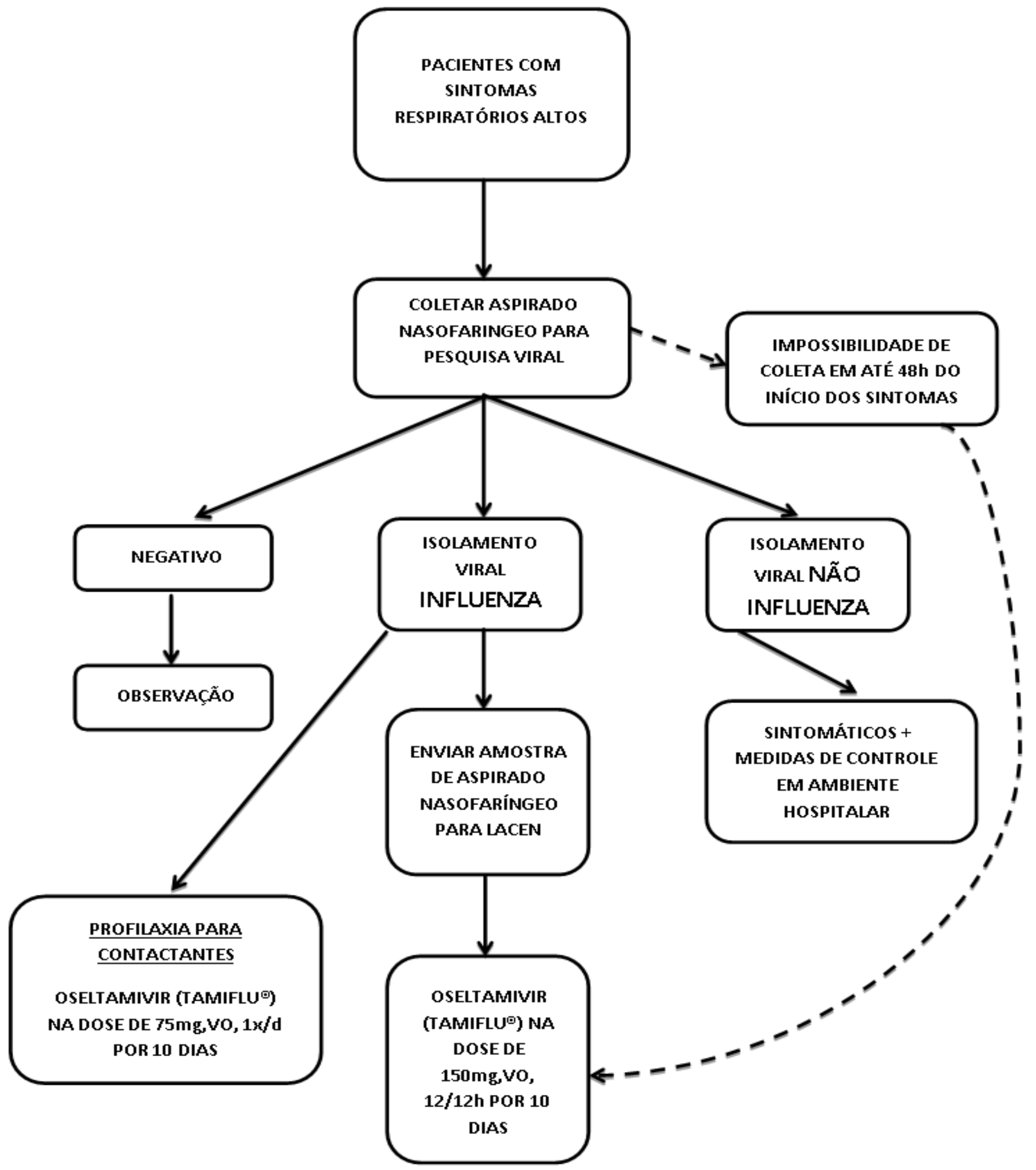




\section{AGRADECIMENTOS}

À equipe da CCIH (Comissão de Controle de Infecção Hospitalar) do Hospital Universitário Walter Cantídio que participou ativamente da discussão desse protocolo.

\section{REFERÊNCIAS}

1. Hirsch HH, Martino R, Ward KN, Boeckh M, Einsele H, Ljungman P. Fourth European Conference on Infections in Leukaemia (ECIL-4): guidelines for diagnosis and treatment of human respiratory syncytial virus, parainfluenza virus, metapneumovirus, rhinovirus, and coronavirus. Clin Infect Dis. 2013;56(2):258-66

2. Shah DP, Ghantoji SS, Mulanovich VE, Ariza-heredia EJ, Chemaly RF. Management of respiratory viral infections in hematopoietic cell transplant recipients. Am J Blood Res [Internet].
À equipe do laboratório de Virologia do Departamento de Patologia e Medicina Legal da Universidade Federal do Ceará que são responsáveis pelas coletas de amostras e identificação de vírus.

2012[acesso 2014 nov 18];2(4):203-18. Disponível em: http://www.ncbi.nlm.nih.gov/pmc/articles/PMC3512176/

3. Jefferson T, Jones M, Doshi P, Spencer EA, Onakpoya I, Heneghan CJ. Oseltamivir for influenza in adults and children: systematic review of clinical study reports and summary of regulatory comments. BMJ. [Internet]. 2014[acesso 2014 nov 18];348:g2545. Disponívelem:.http://www.bmj.com/content/348/bm j.g2545

\section{Como citar:}

Dantas EL, Carvalho LE, Araújo BS, Pitombeira MS, Florêncio CM, Moura FE, et al. Protocolo de manejo de suspeita de infecção viral de vias respiratórias em pacientes com neoplasia hematológica do Serviço de Hematologia e Transplante de Medula Óssea do Hospital Universitário Walter Cantídio (HUWC). Rev Med UFC. 2015 jan-jun;55(1):43-46. 